\title{
Determination of ethylene chlorohydrin as marker of spices fumigation with ethylene oxide
}

\author{
F. Tateo*, M. Bononi \\ Laboratori di Ricerche Analitiche sugli Alimenti, Di. Pro. Ve., Faculty of Agriculture, University of Milan, Via Celoria 2, Milan 20133, Italy
}

Received 14 April 2004; received in revised form 30 November 2004; accepted 1 December 2004

\begin{abstract}
Ethylene oxide (EO) is a gas used to sterilize spices, drugs, packaging materials, medical devices, polyester fibers, plastics and synthetic rubber. When the aeration step foreseen for spices is not properly carried out, residues of EO and its derivative ethylene chlorohydrin $(\mathrm{ECH})$, produced by reaction with chlorine ions always present in the matrix, can be found in these products.

In this way, the reactivity of EO with chlorides in spices provides a suitable marker to confirm the use of EO for fumigation. The ECH derived from spontaneous transformation during the storage and forcibly obtained during the first step of the extraction can be evaluated in spices by a simple GC/MS analytical method, without derivatization.

It has been proven that the EO molecule is carcinogenic for humans; it has been classified as a category 1 carcinogen by the International Agency for Research on Cancer (IARC): $\mathrm{ECH}$, as EO, is a mutagenic substance.

This paper shows the results concerning 25 pepper samples purchased on the Italian market.

The limit of detection for ECH was assumed to be $20 \mu \mathrm{g} / \mathrm{kg}$ (LOD) and was calculated by spiking a matrix pepper that had not been treated with EO. The limit of quantitation was assumed to be $100 \mu \mathrm{g} / \mathrm{kg}$ (LOQ), i.e. 5 times LOD. The reliability of the method was verified by recovery and repeatability tests. Recovery average values are $60-70 \%(\mathrm{CV} \%=9.6-5.5)$ for the concentration range $100-500 \mu \mathrm{g} / \mathrm{kg}$.

Only $56 \%$ of pepper samples analyzed did not contain ECH at detectable levels, and only $24 \%$ of pepper samples contained ECH at levels lower than LOQ. Three samples had a content ranging between 0.2 and $3.3 \mathrm{mg} / \mathrm{kg}$ and two samples showed a content of ECH higher than $5 \mathrm{mg} / \mathrm{kg}$.
\end{abstract}

(C) 2005 Elsevier Inc. All rights reserved.

Keywords: Ethylene Oxide; Ethylene Chlorohydrin; Spices; Fumigation

\section{Introduction}

The method adopted in this work is useful for detecting ethylene chlorohydrin $(\mathrm{ECH})$ as a marker of fumigation of spices with ethylene oxide (EO). The criterion to detect the inclusive sum of $\mathrm{ECH}$ by GC/MS was adopted for the first time; it was derived from spontaneous transformation during storage and forcibly

\footnotetext{
*Corresponding author. Tel.: + 390250316540 ; fax: +390250316539

E-mail address: fernando.tateo@unimi.it (F. Tateo).
}

obtained during the first step of the extraction, without derivatization.

It has been proved that the EO molecule is carcinogenic to humans, and it has been classified as a category 1 carcinogen by the International Agency for Research on Cancer (IARC): ECH and ethylene glycol (EG) are also mutagenic substances. The Scientific Committee on Food on 6 May 2002 concluded that the presence of EO should be brought below the detection limit, and the E.C. fixed purity criteria for defoaming additives E 431, E 432, E 433, E 434, E 435, E 436, and E 459, limiting the EO residues to "not more than $200 \mu \mathrm{g} / \mathrm{kg}$ " (Directive 95/EC, 2003). 
Therefore, as treatment of herbs and spices with EO is not considered a positive quality index, it was opportune to develop a rapid method which was easily applicable and specific to detect the ECH as a marker of fumigation. Therefore, this paper does not aim to suggest an analytical method to detect the residues of $\mathrm{EO}$, as for medical devices sterilized with EO gas; nor is it directed to evaluate the potential toxicity of residues of $\mathrm{EO}$ and $\mathrm{ECH}$ in foods.

When the matrix pepper is fumigated, but the aeration step is not properly carried out, the residue of the EO gas reacts with chlorine ions always present in the matrix to form 2-chloro-ethanol (ECH), which can be found in the treated matrix at levels higher than $20 \mu \mathrm{g} / \mathrm{kg}$.

The results reported in this paper show that, in the case of pepper, a method with LOD $20 \mu \mathrm{g} / \mathrm{kg}$ and LOQ $100 \mu \mathrm{g} / \mathrm{kg}$ is very easy to execute, and is useful for fast quality control.

As pointed out before, the method described in this paper permits the use of a $\mathrm{GC} / \mathrm{MS}$ detector and not a GC or GC/ECD as previously proposed.

The headspace analysis, distillation technique or SPME using the direct-immersion method are considered as suitable methods to determine the mentioned gas if EO is the sole analyte (Ayoub et al., 2002): however EO is both highly reactive and volatile, and very small amounts of the gas are detectable a few days after its use in the fumigation of pepper.

In conclusion, the analytical detection of EO and $\mathrm{ECH}$ for spices is unnecessary since the total effective exposure is shown by all the ECH.

Various authors have published papers about this analytical theme: among our references we believe that the most interesting are the following:

- Jensen (1988) describes a method for the determination of residues of EO and $\mathrm{ECH}$ : sodium hydroxide is added to the sample where ECH is transformed into $\mathrm{EO}$, and the gas is converted into ethylene iodohydrin (EIH) by distillation on dilute sulphuric acid containing sodium iodide. The recoveries of ECH are reported to be $50-60 \%$. The ECH content is determined by gas chromatography using an ECD detector.

- Aitkenhead and Vidnes (1988) propose an acetonitrile-methanol mixture as an extraction solvent for $\mathrm{ECH}$, and capillary GC with FID detector for identification and quantitation of ECH. The authors report that the extraction recovery is approximately $75 \%$ for the extraction procedure.

- Gilsbach and Weeren (1999) refer to an interlaboratory study using the GC method after derivatization with sodium iodide, with recoveries of 66-70\%. Similar procedures are suggested by NIOSH Manual of Analytical Methods (NMAM) (1994) adopting an ECD or MS detector.
This paper provides information about EO treatment of pepper found on Italian markets in family-size packets with EO. Twenty-five pepper samples, representative of most known trademarks and purchased from various Italian supermarkets, have been analysed using the method described below.

\section{Materials and methods}

\subsection{Materials}

Samples of pepper of different varieties and formblack pepper, white pepper, green pepper, ground pepper and peppercorn - were chosen in this study.

All the 25 samples examined, as family-size packets and representatives of packaging commonly used by consumers, were purchased from retailers in Italian markets.

Standard ECH (99\%) from Sigma-Aldrich (Milan, Italy) has been used to prepare standard solutions for calibration; the extraction solvent was ethyl acetate (>99.5\%) from Merck (Milan, Italy).

Standard EO $(50 \mathrm{mg} / \mathrm{mL}$ in methanol) from SigmaAldrich (Milan, Italy) has been used to prepare the solutions to verify the conversion yield of EO to ECH.

\subsection{Apparatus and operating conditions}

A gas chromatograph mass spectrometer QP 2010 system (Shimadzu, Milan, Italy) in EI mode (Electronic Impact), equipped with a polar column SupelcoWax-10 $(30 \mathrm{~m} \times 0.25 \mathrm{~mm}$ ID, $0.25 \mu \mathrm{m}$ film thickness; Supelco, Bellefonte, PA) was used.

A GC oven was programmed: $60^{\circ} \mathrm{C}, 1 \mathrm{~min}, 3{ }^{\circ} \mathrm{C} / \mathrm{min}$ to $240{ }^{\circ} \mathrm{C}, 10 \mathrm{~min}$ at $240^{\circ} \mathrm{C}$.

The injector temperature was kept on $220^{\circ} \mathrm{C}$ (splitless mode $1 \mathrm{~min}$ ). The flow rate of the carrier gas (helium) was $1 \mathrm{~mL} / \mathrm{min}$. The MS detector was operated at $240{ }^{\circ} \mathrm{C}$, ionization energy was $70 \mathrm{eV}$. The detector voltage was set at $0.9 \mathrm{kV}$, and the interface temperature at $200^{\circ} \mathrm{C}$. The solvent delay was $10 \mathrm{~min}$.

The acquisition mode was multiple ion detection (MID) monitoring ions at $m / z=31$ and 80 (rel. abund. 100 and 2 in the ECH standard MS spectrum). The volume injected was $2 \mu \mathrm{L}$.

\subsection{Extraction procedure}

In order to convert completely the residual EO into $\mathrm{ECH}$, an amount of about $2 \mathrm{~g}$ of ground sample (pepper), exactly weighed, was charged with $2 \mathrm{~mL}$ of $0.02 \mathrm{~N} \mathrm{H}_{2} \mathrm{SO}_{4}$ and with $200 \mu \mathrm{L}$ of a saturated solution of $\mathrm{NaCl}$. The sample was extracted twice with $80 \mathrm{~mL}$ of ethyl acetate for $2 \mathrm{~h}$ at $60^{\circ} \mathrm{C}$ by stirring in an ultrasonic bath for $30 \mathrm{~min}$. The ethyl acetate phase was filtered 
Table 1

Conversion yield of standard EO solutions to ECH

\begin{tabular}{llll}
\hline $\begin{array}{l}\text { St.sol ECH } \\
\text { (teor } \mu \mathrm{g} / \mathrm{L})\end{array}$ & $\begin{array}{l}\text { AC measured } \\
(\text { mean of 3 rep) }\end{array}$ & $\begin{array}{l}\text { ECH } \\
(\text { recovered } \\
\mu \mathrm{g} / \mathrm{L})\end{array}$ & $\%$ Conversion \\
\hline 91 & 63552485 & 76 & 84 \\
182 & 130133351 & 157 & 86 \\
364 & 272374299 & 328 & 90 \\
\hline
\end{tabular}

each time on anhydrous sodium sulphate ( $3 \mathrm{~g}$ ), washing the solid residue three times with $10 \mathrm{~mL}$ ethyl acetate and collecting all the resulting liquid phase in a sealed flask. The extract was concentrated in the vacuum of a rotary evaporator to about $1 \mathrm{~mL}$ and then transferred to a 2 or $4 \mathrm{~mL}$ graduated vial, diluting the volume with ethyl acetate.

To verify the conversion yield of EO to ECH, $200 \mu \mathrm{L}$ of standard solutions of EO at conc. of 50, 100 and $200 \mu \mathrm{g} / \mathrm{L}$ are treated as described for pepper, obtaining from each of them $2 \mathrm{~mL}$ of ECH solution theoretically at concentrations of 91,182 and $364 \mu \mathrm{g} / \mathrm{L}$ (Table 1).

The results of the GC/MS analysis are reported below (MID mode, $m / z 31$ and $m / z 80$ ).

\section{Results and discussions}

For the identification of the ECH peak in the extracts, relative intensities for ions $m / z=31$ and 80 were monitored. All peaks of ECH were confirmed also by spiking and by retention time $(13.3 \mathrm{~min}$ in the described GC/MS conditions).

The reliability of the method was verified by recovery and repeatability tests.

Recoveries of added ECH were evaluated by analysing samples, proved to be ECH free, spiked with standard $\mathrm{ECH}$ in the concentration range between 100 and $500 \mu \mathrm{g} / \mathrm{kg}$. Recovery experiments were performed in triplicate and the average values were $65.5 \%$ for pepper spiked at $100-200 \mu \mathrm{g} / \mathrm{kg}(\mathrm{CV} \%=8.4)$ and $70.6 \%$ for pepper spiked at $400-500 \mu \mathrm{g} / \mathrm{kg}(\mathrm{CV} \%=5.5)$.

Repeatibility evaluation tests were carried out on two pepper samples containing ECH at levels of 260 and $3290 \mu \mathrm{g} / \mathrm{kg}$ (mean of five repetitions, corrected by recovery). The $\mathrm{CV} \%$ values were 5.3 for the first and $7.2 \%$ for the second.

The limit of detection for ECH was in the order of $20 \mu \mathrm{g} / \mathrm{kg}$ (LOD) and the limit of quantitation was assumed to be $100 \mu \mathrm{g} / \mathrm{kg}$ (LOQ), i.e. five times that for LOD. The LOD value was estimated not only from the noise value but by considering the minimum peak which produced an MID identifiable as a characteristic of $\mathrm{ECH}$.

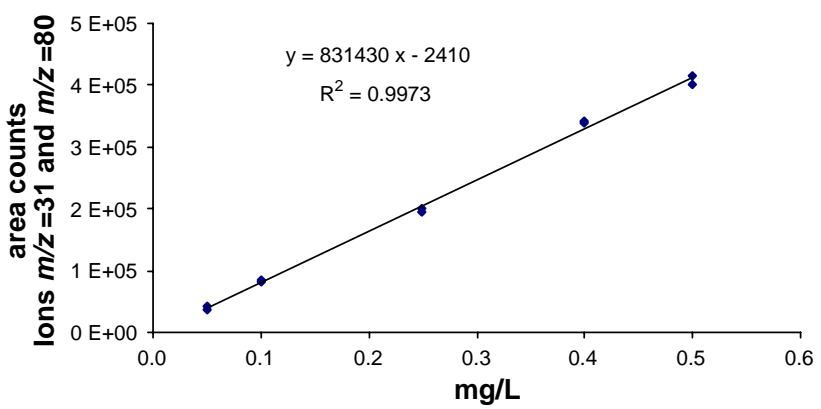

Fig. 1. Calibration curve of standard ECH solution in ethyl acetate in the concentration range $0.050-0.500 \mathrm{mg} / \mathrm{L}\left(R^{2}=0.9973\right)$.

Linearity was tested $\left(R^{2}=0.9973\right)$ using a standard solution of $\mathrm{ECH}$ in ethyl acetate in a concentration range between 0.050 and $0.500 \mathrm{mg} / \mathrm{L}$, monitoring the calibration curve (Fig. 1) and the area count of the ion at $m / z=31$. No interference with this peak was found after analyzing a large number of pepper samples which were certainly not fumigated.

The calibration curve enables the detection of $\mathrm{ECH}$ levels in the sample not exceeding $4 \mathrm{mg} / \mathrm{kg}$, considering that is possible to use not less then $0.5 \mathrm{~g}$ of sample for the extraction and to dilute the extract to $4 \mathrm{~mL}$. For levels of $\mathrm{ECH}>4 \mathrm{mg} / \mathrm{kg}$ in the sample it is necessary to dilute the extract before injection, to avoid detector saturation.

Considering the aim of the application of this method, it is not necessary to do the quantitation of $\mathrm{ECH}$ at levels more than $4 \mathrm{mg} / \mathrm{kg}$ in pepper samples (i.e. $5.7 \mathrm{mg}$ / $\mathrm{kg}$, corrected by recovery $70 \%$ ), not reaching the level of $100 \mu \mathrm{g} / \mathrm{kg}$ and not exceeded by involuntary or crossshaped pollution events. When the ECH level is higher than the value mentioned earlier a quantitative evaluation can be made using a larger dilution of the extract. The results of the research carried out in this work, for the reasons explained before, were expressed as $>5.0 \mathrm{mg} / \mathrm{kg}$ when the level of ECH was higher than $5 \mathrm{mg} / \mathrm{kg}$.

To estimate the level of $\mathrm{ECH}$ in the sample the quantitative calculation was processed as follows:

$C_{\mathrm{c}}=\left(C_{\mathrm{e}} \times V_{\mathrm{e}} \times 100\right) /\left(P_{\mathrm{c}} \times R\right)$,

where $C_{\mathrm{c}}$ is the concentration of $\mathrm{ECH}$ resulting in the sample $(\mathrm{mg} / \mathrm{kg}), C_{\mathrm{e}}$ the concentration of ECH calculated from the calibration curve $(\mathrm{mg} / \mathrm{L}), V_{\mathrm{e}}$ the volume of the reconstituted extract $(2-4 \mathrm{~mL}), P_{\mathrm{c}}$ the weight of the sample $(\mathrm{g})$ and $R$ the recovery $\%$.

The MS spectrum in scan mode corresponding to a standard solution of ECH is reported in Fig. 2.

Fig. 3 shows the GC/MS trace of an extract, produced with the method described before, from a pepper sample proved to be ECH free, and spiked with $\mathrm{ECH}$ at $0.020 \mathrm{mg} / \mathrm{kg}$ (LOD). Fig. 4 reports, as a further example, the GC/MS trace of an extract produced from a pepper 


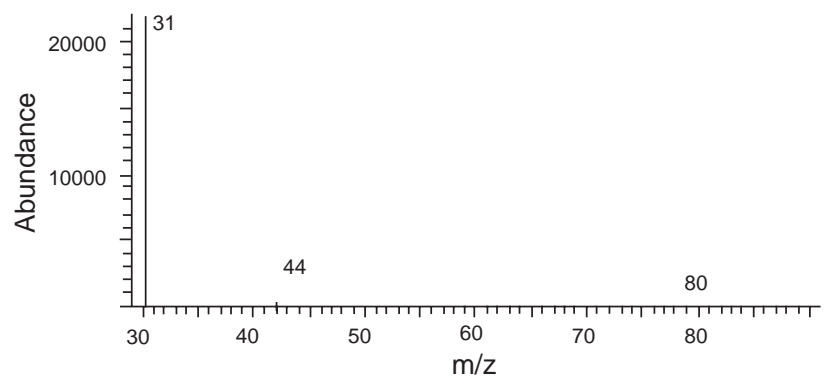

Fig. 2. MS spectrum produced by standard ECH in scan mode.

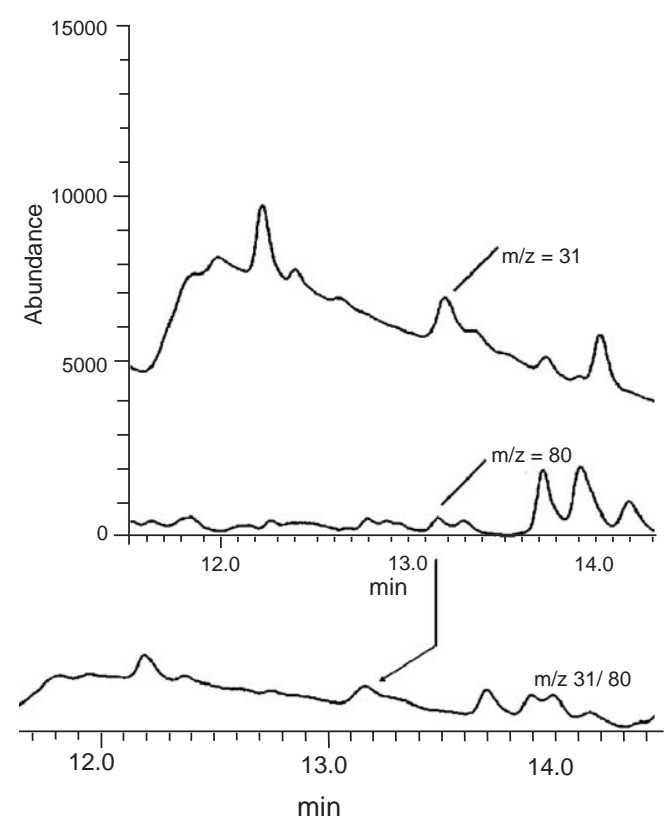

Fig. 3. GC/MS trace $(m / z=31$ and 80$)$ of an extract obtained from a pepper sample spiked with ECH at $0.020 \mathrm{mg} / \mathrm{kg}$ (LOD).

sample containing $\mathrm{ECH}$ at $0.630 \mathrm{mg} / \mathrm{kg}$, mentioned among the quantitative results shown in Fig. 5. The two figures show the traces of the ions at $m / z=$ 31 and 80 for the peak eluted at $13.3 \mathrm{~min}$ : the ion ratios and the retention time clearly identify the peak as $\mathrm{ECH}$.

25 samples of commercial pepper from the Italian market were analysed, as described in "Materials and methods". Table 2 reports the label information concerning the examined products, and quantitative results are summarized in Fig. 5, and corrected with recovery data.

The review carried out in this study led to these conclusions: fourteen samples were found to have an $\mathrm{ECH}$ level $<\mathrm{LOD}$, six samples produced a content

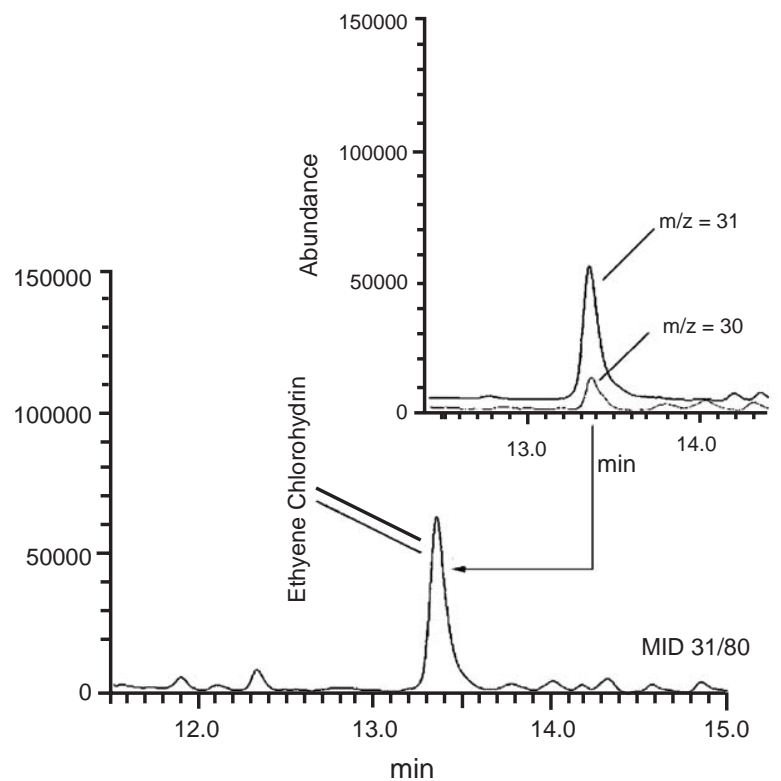

Fig. 4. GC/MS trace $(m / z=31$ and 80$)$ of an extract obtained from a pepper sample containing $0.634 \mathrm{mg} / \mathrm{kg}$ of $\mathrm{ECH}$.

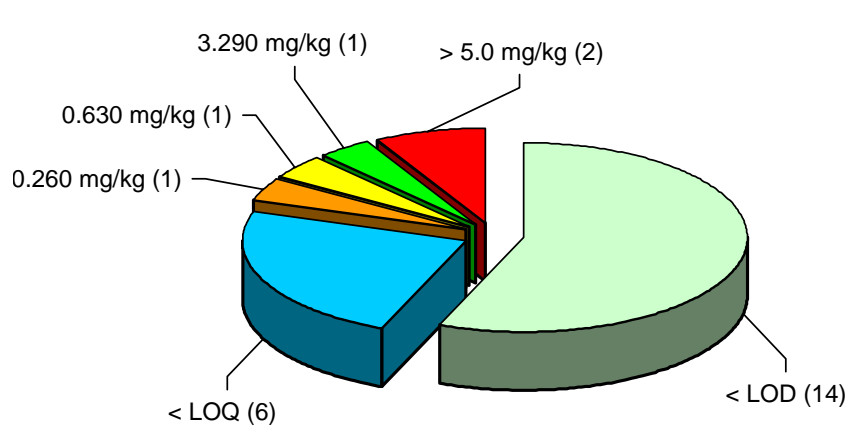

Fig. 5. Distribution of ECH level in 25 pepper samples mentioned in Table 1; the number of samples is reported in round brackets.

between LOD and LOQ and the remaining five samples contained ECH at levels between 0.260 and $>5.0 \mathrm{mg} / \mathrm{kg}$.

The results obtained show that 11 of the 25 examined samples present $\mathrm{ECH}$ at a level higher than $0.020 \mathrm{mg} / \mathrm{kg}$ (LOD) and in two samples the content is higher than $5 \mathrm{mg} / \mathrm{kg}$. In conclusion, $44 \%$ of the Italian market's most representative samples are found to be fumigated with EO.

The research emphasizes the current problem concerning industrial chemical residues in food. The simple analytical procedure, and the short time required for extraction and GC/MS analysis, allow the consideration of the method adopted in this paper as being useful for routine analysis of pepper or other spices fumigated with EO. 
Table 2

Label information for 25 variuos peppers sold in Italian market

\begin{tabular}{|c|c|c|c|c|}
\hline & Sample description & Lot & Expiry date & Net weight $(\mathrm{g})$ \\
\hline 1 & Black pepper "Ducros" & L3094C & $04 / 2006$ & 48 \\
\hline 2 & White pepper "Ducros" & L3070C & $03 / 2006$ & 48 \\
\hline 3 & Black pepper "Drogherie alimentari" & L22073 & $08 / 09 / 2006$ & 40 \\
\hline 4 & White pepper "Drogherie alimentari" & L06033 & $13 / 06 / 2006$ & 40 \\
\hline 5 & White pepper "Mondo natura" & L120328 & $16 / 07 / 2005$ & 45 \\
\hline 6 & Black pepper "Cannamela" bionatura & - & $28 / 08 / 2006$ & 50 \\
\hline 7 & Black pepper "Cannamela" & - & $29 / 11 / 2004$ & 28 \\
\hline 8 & White pepper "Cannamela" & - & 09/04/2006 & 28 \\
\hline 9 & Black peppercorn "Cannamela" & - & $23 / 09 / 2005$ & 28 \\
\hline 10 & White peppercorn "Cannamela" & - & $14 / 04 / 2006$ & 28 \\
\hline 11 & Black pepper "Alpes" & - & $20 / 03 / 2006$ & 9 \\
\hline 12 & White pepper "Alpes" & - & $20 / 03 / 2006$ & 8 \\
\hline 13 & Black pepper "Kania" & 3014BB & 2007 & 50 \\
\hline 14 & White pepper "Kania" & $3281 \mathrm{AC}$ & 2007 & 50 \\
\hline 15 & Black pepper "Tesori dell'arca" & L3020 & $20 / 01 / 2006$ & 50 \\
\hline 16 & White pepper "Tesori dell'arca" & L3017 & $17 / 01 / 2006$ & 50 \\
\hline 17 & Black peppercorn "Fertitecnica Colfiorito" & L3182 & $30 / 07 / 04$ & 300 \\
\hline 18 & White pepper "Fertitecnica Colfiorito" & L3143 & $30 / 05 / 04$ & 300 \\
\hline 19 & Black pepper "Il Gigante" & L220736 & $08 / 09 / 2006$ & 40 \\
\hline 20 & White pepper "Il Gigante" & L120236 & $19 / 05 / 2006$ & 40 \\
\hline 21 & Black peppercorn "Il Gigante" & $\mathrm{L} 25102 \mathrm{~N}$ & $16 / 04 / 2006$ & 45 \\
\hline 22 & Green peppercorn "Il Gigante" & L200238 & $18 / 03 / 2006$ & 15 \\
\hline 23 & Black peppercorn "Tropic all" & L3203 & $07 / 2006$ & 50 \\
\hline 24 & Black pepper "Shapur" & $130 \times 1833$ & $31 / 12 / 2007$ & 30 \\
\hline 25 & White pepper "Shapur" & W5121833 & $31 / 12 / 2007$ & 30 \\
\hline
\end{tabular}

\section{Acknowledgements}

G. Pezzotta and G. Andreoli provided analytical collaboration for analytical work and A.Varani provided collaboration in editorial work.

\section{References}

Aitkenhead, P., Vidnes, A., 1988. Simple and accurate method for determination of ethylene chlorohydrin in dried spices and condiments. J. Assoc. Off. Anal. Chem. 71, 729-731.

Ayoub, K., Harris, L., Thompson, B., 2002. Determination of low-level residual ethylene oxide by using solid-phase micro- extraction and gas chromatography. J. AOAC Int. 85 (6), 1205-1209.

Directive 95/EC, 2003. Commission directive of 27 October 2003 amending directive 96/77/EC laying down specific purity criteria on food additives other than colours and sweeteners. Official Journal of the European Union L 283, 31.10.2003.

Gilsbach, W., Weeren, R.D., 1999. Ringuntersuchungen zur Validierung einer gaschromatographischen Methode zur Bestimmung von Rückständen an Ethylenoxid und 2-Chloroethanol in Gewürzen aus Paprika und Chili, Dtsch. Lebensm. Rundsch. 95, 83-90.

Jensen, K.G., 1988. Determination of ethylene oxide residues in processed food products by gas-liquid chromatography after derivatization. Z. Lebensm Unters Forsch 187, 535-540.

Niosh Manual of Analytical Methods (NMAM), 1994. Fourth Edition, 8/15/94. 